\title{
Cytotoxic Effect of Fucoxanthin Isolated from Selected Sargassum Species of South East Coast, India
}

\begin{abstract}
Background: Fucoxanthin is known for various biological activities and has been isolated for its bioactivity from Sargassum fulvellum, Sargassum heterophyllum, Sargassum horneri, Sargassum siliquastrum, Sargassum wightii, Sargassum ilicifolium, Sargassum longifolium. But there is no report on the isolation of fucoxanthin from Sargassum polycystum C. Agardh, Sargassum swartzii (Turner) C. Agardh and Sargassum johnstonii Setchell \& N.L.
\end{abstract}

Aim: The present study was aimed to optimize the protocol for the isolation of fucoxanthin from Sargassum polycystum C. Agardh, Sargassum swartzii (Turner) C. Agardh and Sargassum johnstonii Setchell \& N.L. Gardner and evaluate their cytotoxic potentials against brine shrimp (Artemia salina) naupli.

Methods: One gram of powdered seaweed was weighed and dissolved in $10 \mathrm{ml}$ of $90 \%$ acetone. The fucoxanthin was observed by measuring the UV-Vis (UV-Vis = Ultra Violet- Visible light) spectra of the solution at 200-1100 nm (Lamda max) using Shimadzu spectrophotometer and the characteristic peaks were detected. Silica gel coated plates (Merck - 10×6 cm) and n-hexane: acetone was used as mobile phase for the separation with a ratio of 7:3. For cytotoxic analysis, fucoxanthin extracts of S. johnstonii, S. swartzii and S. polycystum were taken in different concentrations viz., $50,100,150,200,250 \mu \mathrm{g} / 50 \mathrm{ml}$. The $\mathrm{LC}_{50}$ (LC= Lethal concentration )was calculated for Package for Social Studies (SPSS).

Results: The quantiative occurrence of the fucoxanthin in the studied seaweeds as follows $S$. swartzii $>$ S. polycystum $>$ S. johnstonii. The UV-Vis analysis confirmed the existence of fucoxanthin in the thallus of $S$. johnstonii, S. swartzii and S. polycystum. Acetone extracts of $S$. johnstonii, $S$. swartzii and $S$. polycystum showed single fucoxanthin band with Rf value $0.4782,0.4565$ and 0.5 respectively. The fucoxanthin isolated from $S$. johnstonii demonstrated the lowest $\mathrm{LC}_{50}$ ( $\mathrm{LC}=$ Lethal concentration) value with $338.2 \mu \mathrm{g} / 50 \mathrm{ml}$, next to that $S$. swartzii $(423.47 \mu \mathrm{g} / 50 \mathrm{ml})$ and $S$. polycystum $(434.57 \mu \mathrm{g} / 50 \mathrm{ml})$.

Conclusion: The results of the present study clearly validated the cytotoxic potentials of the S. johnstonii, S. swartzii and S. polycystum fucoxanthin.

Keywords: Fucoxanthin; Sargassum; Cytotoxic; Anti-oxidant; Anti-tumor; Antiinflammatory the isolated fucoxanthin of $S$. johnstonii, S. swartzii and S. polycystum using Sofware

Research Article
Volume 10 Issue 1 - 2017
Johnson M*, Chandlrakalla P and Shibilla T
Research Department of Botany, Centre for Plant
Biotechnology, India
*Corresponding author: M Johnson, Director, Centre for
Plant Biotechnology, Research Department of Botany, St.
Xavier's College (Autonomous), Palayamkottai, Tamil Nadu,
India - 627 002, Tel: + 91 9786 92 4334; Fax: + 91462 2560
765; Email: ptcjohnson@gmail.com
Received: February 10, 2017 | Published: December 12,
2017

\section{Introduction}

Fucoxanthin is known for anti-oxidant, anti-tumor, antiinflammatory, and anti-obesity effects [1-5]. Fucoxanthin has been isolated for its bioactivity from Sargassum fulvellum [6] Sargassum heterophyllum [7], Sargassum horneri [8], Sargassum siliquastrum [3] Sargassum wightii, Sargassum ilicifolium, Sargassum longifolium [9]. Cytotoxicity of aqueous and AgNPs of S. johnstonii and $S$. polycystum against Dalton's lymphoma ascites (DLA) cells and Artemia salina $[10,11]$ and Undaria pinnatifida were reported $[12,13]$. Anticancer activity of Sargassum oligocystum, Sargassum swartzii, Sargassum pallidum, Sargassum turtile and Sargassum latifolium were noted by the phycologist [14-18]. But there is no report on the isolation of fucoxanthin from Sargassum polycystum C. Agardh, Sargassum swartzii (Turner) C. Agardh and Sargassum johnstonii Setchell \& N.L. With this knowledge, the present study was aimed to optimize the protocol for the isolation fucoxanthin from Sargassum polycystum C. Agardh, Sargassum swartzii (Turner) C.Agardh and Sargassum johnstonii Setchell \& N.L. Gardner and evaluate their cytotoxic potentials against brine shrimp (Artemia salina) naupli.

\section{Methods and Materials}

The mature and healthy thallus of Sargassum polycystum C. Agardh, Sargassum swartzii (Turner) C. Agardh and Sargassum johnstonii Setchell \& N.L. Gardner were collected from Manapad, Tirunelveli district, Tamil Nadu and Rasthacaud, Kanyakumari District Tamil Nadu. The collected seaweeds were shade dried at room temperature under dark conditions and the shade dried thallus was separately powdered. The powdered samples were stored in polythene bags and used for further analysis. 
One gram of powdered seaweed was weighed and dissolved in $10 \mathrm{ml}$ of $90 \%$ acetone (HiMedia, Mumbai, India). The samples were incubated for overnight at $4{ }^{\circ} \mathrm{C}$ in a dark place and then centrifuge at $8000 \mathrm{rpm}$ for $15 \mathrm{~min}$. Extraction was repeated three times till the sample become colourless. The procedure was carried out in triplicates. The sample was stored in amber colour bottles to avoid degradation by light. The fucoxanthin extracts of $S$. johnstonii, $S$. swartzii and $S$. polycystum were centrifuged at $3000 \mathrm{rpm}$ for $10 \mathrm{~min}$ and then filtered through Whatman No. 1 filter paper. The fucoxanthin was observed by measuring the UV-Vis spectra of the solution at 200-1100 nm using Shimadzu spectrophotometer and the characteristic peaks were detected. Each and every analysis was repeated twice and confirmed the spectrum

Thin layer chromatography was used to separate the pigments and find out the Rf value of the photosynthetic pigment fucoxanthin present in S. johnstonii, S. swartzii and S. polycystum. Pigments in the mixture are separated on the basis of their differences in solubilities and partition co-efficient in a binary solvent system. Silica gel coated plates (Merck - $10 \times 6 \mathrm{~cm}$ ) and n-hexane: acetone (HiMedia, Mumbai, India) was used as mobile phase for the separation with a ratio of 7:3 [19].

To know the cytotoxic potentials of selected seaweeds, the brine shrimp bioassay was perfomed [20].25mg of dried fucoxanthin extracts of $S$. johnstonii, $S$. swartzii and $S$. polycystum was taken in $10 \mathrm{ml}$ beaker and $500 \mu \mathrm{l}$ DSO (HiMedia, Mumbai, India) was added to it. Finally the volume $(5 \mathrm{ml})$ was adjusted by distilled water. The concentration of this solution was $5 \mu \mathrm{g} / \mu \mathrm{l}$. Fucoxanthin extracts of $S$. johnstonii, $S$. swartzii and $S$. polycystum were taken in different concentrations viz., 50,100, 150, 200, $250 \mu \mathrm{g} / 50 \mathrm{ml}$ After 24 hours, the tubes were inspected using a magnifying glass and the number of survived nauplii in each tube was counted and the $\mathrm{LC}_{50}, 95 \%$ confidence limit, LCL and UCL were calculated.

\section{Results}

Fucoxanthin is one of the most profused carotenoids present in the edible brown algae. In the present study also the occurrence of fucoxantin was validated in three studied Sargassum species. Among the three seaweeds studied, S. swartzii contained high content of fucoxanthin compared to other two studied Sargassum species. The quantiative occurrence of the fucoxanthin in the studied seaweeds were as follows $S$. swartzii $(0.073 \mathrm{mg}$ g- $1 \mathrm{DW})$ $>$ S. polycystum $(0.055 \mathrm{mg} \mathrm{g-1} \mathrm{DW})>$ S. johnstonii $(0.014 \mathrm{mg} \mathrm{g}-1$ DW). The UV-Vis analysis confirmed the existence of fucoxanthin in the thallus of $S$. johnstonii, S. swartzii and S. polycystum (Figure $1 \mathrm{~A}-\mathrm{C})$. The fucoxanthin isolated from the thallus of $S$. johnstonii showed the optical peak at 664 and $404 \mathrm{~nm}$ with the absorption of 1.750 and 3.957 respectively (Figure 1A). S. swartzii illustrated the optical peak at 664 and $416 \mathrm{~nm}$ with the absorption of 2.153 and 4.000 respectively (Figure 1B). S. polycystum explained the optical peak at 664 and $412 \mathrm{~nm}$ with the absorption of 2.340 and 4.110 respectively (Figure $1 \mathrm{C}$ ). TLC separation of $S$. johnstonii, $S$. swartzii and $S$. polycystum acetone extracts confirmed the fucoxanthin occurrence (Figure 1D). Acetone extracts of $S$. johnstonii, S. swartzii and S. polycystum showed single fucoxanthin band with Rf value $0.4782,0.4565$ and 0.5 respectively. The fucoxanthin isolated from $S$. johnstonii demonstrated the lowest $\mathrm{LC}_{50}$ value with $338.2017 \mu \mathrm{g} / 50 \mathrm{ml}$, next to that $S$. swartzii (423.47 $\mu \mathrm{g} / 50 \mathrm{ml})$ and S. polycystum $(434.57 \mu \mathrm{g} / 50 \mathrm{ml})$.
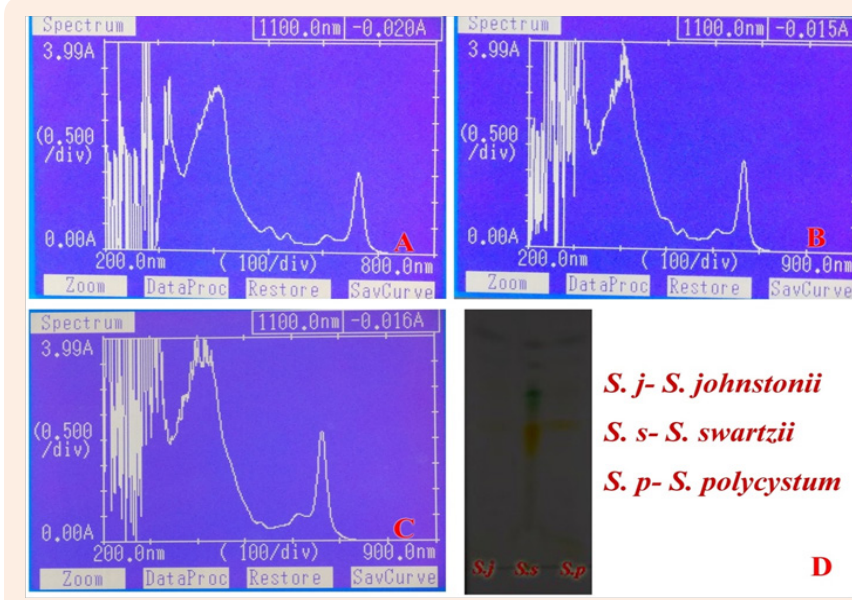

Figure 1: UV-Vis spectrum and TLC profile of Fucoxanthin.

A: UV-Vis spectrum of $S$. johnstonii; B: UV-Vis spectrum of $S$. swartzii; C: UV-Vis spectrum of S. polycystum; D: TLC profile of fucoxanthin extracts of studied Sargassum species; S. j:- S. johnstonii; S. $s$ - S. swartzii; S. p: S. polycystum.

\section{Discussion}

Globally phycologist and pharmacologist are paid attention to fucoxanthin due to their biopotentials especially as chemopreventive and chemotherapeutic agent [21]. Similarly the same compound has been identified in the crude extract of brown seaweed Himanthalia elongate at 331 nm, 446 and 468 using UVvisible spectroscopy [22]. Zailanie [23] identified fucoxanthin in Sargassum filipendula at $450 \mathrm{~nm}$. In addition to quantification, The UV-Vis analysis results exhibited novel markers for the identification of S.johnstonii, S. swartziiand S. polycystum. These UVVis spectroscopic peaks may be employed as pharmacognostical marker for the identification of the studied Sargassum species. The observed TLC profiles may used as biochemical marker to distinguish Sargassum species from its adulterants in the pharmaceutical industries. Fucoxanthin extracts of $S$. johnstonii, S. swartzii and S. polycystum showed different mortality rate of brine shrimp, which increased proportionally with the increasing concentration of the extracts. The inhibitory effect of the extract might be due to the toxic compounds present in the fucoxanthin extracts of S. johnstonii, S. swartzii and S. polycystum.

Chandra Kala et al. [10] studied the cytotoxic properties of aqueous extracts and AgNPs of Sargassum johnstonii. They observed the cytotoxic potential of $S$. johnstoniisilver nanoparticles showed least $\mathrm{LC}_{50}$ value at $656.89 \mu \mathrm{g} / \mathrm{ml}$. Similary the AgNPs of Sargassum polycystum also showed the cytotoxic effect with $\mathrm{LC}_{50}$ $502.72 \mu \mathrm{l} / \mathrm{ml}$ against Artemia salina and with $\mathrm{CTC}_{50}$ at $188.64 \mu \mathrm{l} /$ $\mathrm{ml}$ in AgNPs of $S$. polycystum [11]. In the present study also the fucoxanthin of $S$. johnstonii and $S$. polycystum showed least $\mathrm{LC}_{50}$ value compared to the aqueous extracts and AgNPs of $S$. 
johnstonii and S. polycystum. The results of the present study clearly validated the cytotoxic properties of fucoxanthin isolated from the S. johnstonii and S. polycystum. The results of the present study supplemented the previous observations. Khanavi et al. [15] observed the anticancer activity in Sargassum swartzii against Caco-2 and T47D cell lines.

\section{Conclusion}

The results of the present study also supplemented the Khanavi et al. observations. Thus the results of the present study revealed the cytotoxic properties of $S$. johnstonii, S. swartzii and $S$. polycystum. These may be used as an alternative anticancer drug for the future. In addition the result of the spectroscopic and TLC analysis produced novel pharmacognostical and phytochemical markers for the medicinally important seaweeds $S$. johnstonii, S. swartzii and S. polycystum. These profiles may be used in the pharmaceutical industries to identify the medicinal source $(S$. johnstonii, S. swartzii and S. polycystum) from its adulterants.

\section{Conflict of Interest}

The authors declare that there is no conflict of the interest in the present study.

\section{Acknowledgement}

None.

\section{References}

1. Heo SJ, Yoon WJ, Kim KN, Oh C, Choi YU, et al. (2012) Antiinflammatory effect of fucoxanthin derivatives isolated from Sargassum siliquastrum in lipopolysaccharide-stimulated RAW 264.7 macrophage. Food Chem Toxicol 50(9): 3336-3342.

2. Heo SJ, Jeon YJ (2009) Protective effect of fucoxanthin isolated from Sargassum siliquastrum on UV-B induced cell damage. J Photochem Photobiol 95(2): 101- 107.

3. Kim KN, Ahn G, Heo SJ, Kang SM, Kang MC, et al. (2013) Inhibition of tumor growth in vitro and in vivo by fucoxanthin against melanoma B16F10 cells. Environ. Toxicol Pharmacol 35(1): 39-46.

4. Heo SJ, Ko SC, Kang SM, Kang HS, Kim JP, Kim SH, et al. (2008) Cytoprotective effect of fucoxanthin isolated from brown algae Sargassum siliquastrum against $\mathrm{H}_{2} \mathrm{O}_{2}$-induced cell damage. Eur Food Res Technol 228(1): 145-151.

5. Kim KN, Heo SJ, Kang SM, Ahn G, Jeon YJ (2010) Fucoxanthin induces apoptosis in human leukemia HL-60 cells through a ROS-mediated Bcl-xL pathway. Toxicol Vitro 24(6): 1648-1654.

6. Yu RX, Hu XM, Xu SQ, Jiang ZJ, Yang W (2011) Effects of fucoxanthin on proliferation and apoptosis in human gastric adenocarcinoma MGC-803 cells via JAK/ STAT signal pathway. Eur J Pharmacol 657(1-3): 10-19.

7. Yan X, Chuda Y, Suzuki M, Nagata T (1999) Fucoxanthin as the major antioxidant in Hijikia fusiformis, common edible seaweed. Biosc Biotechnol Biochem 63(3): 605-607.

8. Heo SJ, Jeon YJ (2009) Protective effect of fucoxanthin isolated from Sargassum siliquastrum on UV-B induced cell damage. J Photochem Photobiol 95(2): 101- 107.
9. Sudhakar MP, Ananthalakshmi JS, Beena BN (2013) Extraction, purification and study on antioxidant properties of fucoxanthin from brown seaweeds. Journal of Chemical and Pharmaceutical Research 5(7): 169-175.

10. Chandra Kala P, Johnson M, Shibila T, Revathy I (2015) Synthesis and characterization of cytotoxic silver nanoparticles using marine brown seaweed Sargassum johnstonii Setchell \& N.L. Gardner World Journal of Pharmaceutical Research 4(9): 1545-1555.

11. Asha Kanimozhi S, Johnson M, Chandra Kala P, Shibila T, Revathy I (2015) Extracellular synthesis of silver nanoparticles from a marine alga, Sargassum polycystum C. Agardh and their biopotentials. World Journal of Pharmacy and Pharmaceutical Sciences 4(9): 1388-1400.

12. Nakazawa Y, Sashima T, Hosokawa M, Miyashita K (2011) Comparative evaluation of growth inhibitory effect of stereoisomers of fucoxanthin in human cancer cell lines. J Funct Foods 1(1): 88-97.

13. Okada T, Mizuno Y, Sibayama S, Hosokawa M, Miyashita K (2011) Antiobesity effects of Undaria lipid capsules prepared with scallop phospholipids. J Food Sci 76(1): H2-H6.

14. Zandi K, Ahmadzadeh S, Tajbakhsh S, Rastian Z, Yousefi F, et al. (2010) Anticancer activity of Sargassum oligocystum water extract against human cancer cell lines. Eur Rev Med Pharmacol Sci 14(8): 669-673.

15. Khanavi M, Nabavi M, Sadati N, Shams AM, Sohrabipour J, Nabavi SM, et al. (2010) Cytotoxic activity of some marine brown algae against cancer cell lines. Biol Res 43(1): 31-37.

16. Ye H, Wang K, Zhou C, Liu J, Zeng X (2008) Purification, antitumor and antioxidant activities in vitro of polysaccharides from the brown seaweed Sargassum pallidum. Food Chem 111(2): 428-432.

17. Numata A, Kanbara S, Takahashi C, Fujiki R, Yoneda M, et al. (1992) A cytotoxic principle of the brown alga Sargassum tortile and structures of chromenes. Phytochemistry 31(4): 1209-1213.

18. Gamal-Eldeen AM, Ahmed EF, Abo-Zeid MA (2009) In vitro cancer chemopreventive properties of polysaccharide extract from the brown alga, Sargassum latifolium. Food Chem Toxicol 47(6): 13781384 .

19. Haugan JA, Aakermann T, Jensen SL (1992) Isolation of fucoxanthin and peridinin, Methods in Enzymology 213: 231-245.

20. McLaughlin JL, Chang CJ, Smith DL (1991) Bench-top bioassays for the discovery of bioactive natural products: an update, In: Rhaman AU (Editor) Studies in Natural Products Chemistry. Elseiver 112137.

21. Peng J, Yuan J, Wu C, Wang J (2011) Fucoxanthin, a marine carotenoid present in brown seaweeds and diatoms: metabolism and bioactivities relevant to human health. Marine Drugs $9(10)$ : 1806-1828.

22. Gaurav R, Nissreen A (2013) Isolation and partial characterization of bioactive fucoxanthin from Himanthalia elongata Brown seaweed: A TLC- based approach. International Journal of Analytical Chemistry 1- 6.

23. Zailanie P (2011) Fucoxanthin content of five species brown seaweed from Talango District, Madura Island. Journal of agricultural science and technology 1: 1103-1105. 